\title{
A relação campo-cidade na Geografia Brasileira: apontamentos teóricos a partir de periódicos científicos
}

Flamarion Dutra Alves*

Resumo: Esta pesquisa trata da evolução da temática campo-cidade na geografia brasileira partindo de 1939 a 2009, baseada em artigos publicados em dez periódicos científicos em geografia. 0 artigo apresenta os diferentes modos de investigação por parte dos geógrafos, no que tange a relação campo-cidade, desde uma visão dicotômica e pouco interligada na geografia clássica, passando pelos usos de modelos espaciais e quantitativos na geografia teorética (ainda com pouca integração dos espaços rurais e urbanos), até as questões associadas e interligadas dos espaços periurbanos, rururbanos e contínuos na combinação das estruturas e processos dos espaços rurais e urbanos da geografia contemporânea.

\section{The countryside-city relation in Brazilian Geography: theoretical notices from scientific journals}

\begin{abstract}
This research deals with the evolution of the countryside-city issue in Brazilian Geography from 1939 until 2009. It is based on essays published in ten Geography scientific journals. The essay presents the geographers' varied ways of investigation, regarding the relation countryside-city, from a dichotomist and little interconnected view in classical Geography, going through the uses of spatial and quantitative standards in theoretic Geography (it is still an area with little interconnection of the urban with rural spaces), until the issues associated with and linked to the peri-urban, rur-urban and continuous spaces in the combination of structures and processes of the rural and urban spaces in contemporary Geography.
\end{abstract}

* Professor Adjunto do Curso de Geografia e Líder do Grupo de Estudos Regionais e Socioespaciais (GERES) Universidade Federal de Alfenas (UNIFAL/MG).

Palavras-chave: História do pensamento geográfico; Dinâmica espacial; Ruralurbano; Epistemologia.

Key-Words: History of Geographic Thought; Spatial Dynamics; Countryside-Urban; Epistemology; Amazonie. 


\section{Introdução}

A questão campo-cidade e rural-urbano vem sendo debatida de diferentes formas ao longo das décadas pelas ciências humanas e sociais, e a geografia tem desempenhado um papel importante nessas discussões, sobretudo a partir da década de 1990.

Esta pesquisa acerca das questões teórico-metodológicas da geografia agrária brasileira é fruto da tese de doutorado desenvolvida por Alves (2010) que trata dos temas, teorias, métodos e conceitos utilizados ao longo de setenta anos, entre 1939 a 2009, nas revistas científicas de geografia.

Constatou-se que a abordagem sobre a questão campo-cidade acompanhou 0 desenvolvimento do pensamento geográfico, ou seja, os estudos das relações dos espaços rurais e urbanos tiveram os prismas epistemológicos da corrente clássica, teorética, crítica e cultural.

Numa perspectiva da descrição das paisagens rurais e urbanas o enfoque dessa relação foi dicotômico tratando de dois espaços distintos quanto sua forma, função e processos contraditórios.

Nessa mesma visão paradigmática da geografia, o espaço rural é o lugar para a produção de alimentos, atividades agropecuárias à serviço e abastecimento das cidades. Os trabalhos de Bertha Becker (1966), La Corte (1976) e Manuel Seabra (1969) evidenciam essa questão, no qual abordam a relação econômica existente entre campo e cidade no viés produtivista.

A tendência teorética na relação campo-cidade aparecerá com os modelos espaciais de Von Thünen e Christaller, com a questão do planejamento regional, mas o objetivo central dos estudos nessa ótica está no econômico, ou seja, organizar o espaço para diminuição dos custos de transporte entre centro e os locais de produção. No estudo de Von Thünen destaca-se a pesquisa de Mesquita (1978), enquanto o modelo de Christaller foi abordado por Duarte (1977).

A partir da década de 1990 as pesquisas envolvendo a temática campo-cidade ganham uma denotação com viés crítico e caráter socioespacial. Os estudos envolvendo aspectos políticos, sociais e com outras enfoques acerca da relação campo-cidade foram debatidas por Alentejano $(2000,2003)$ ao discorrer sobre o "Novo Rural" e suas relações socioespaciais.

Hespanhol e Hespanhol (2006) também tecem argumentos a respeito da relação campocidade numa dimensão e desenvolvimento territorial a partir da década de 1990. Os estudos partem para um diálogo de continuum dos espaços rurais e urbanos, ou seja, as ruralidades estão presentes na cidade, assim como as urbanidades estão no rural, conforme aponta Rua (2005). Estas relações estão notadamente aos aspectos culturais e sociológicos da população dos lugares, e a utilização de autores da sociologia são fortemente empregados na base teórica dos geógrafos, em especial Maria José Carneiro, Maria Nazareth Wanderley e o economista José Eli da Veiga. Isso aponta para um pluralismo teórico-metodológico na perspectiva campo-cidade neste início de século XXI na geografia.

Assim, a pesquisa sobre a evolução da relação campo-cidade parte da análise de artigos em periódicos selecionados ao longo de 70 anos (1939-2009) procurando evidenciar as terminologias, temáticas e considerações acerca da dinâmica rural-urbana no Brasil.

\section{Aspectos metodológicos da investigação}

Geografia Ensino \& Pesquisa, v. 16, n.3 p. 7-18, set./dez. 2012

A relação campo-cidade na Geografia brasileira: apontamentos teóricos a partir de periódicos científicos
O processo investigativo da história do pensamento geográfico pode ser realizado de diversas maneiras para elucidar as questões teóricas e metodológicas do pesquisador, escola ou ramo da geografia. Os textos representam um mosaico de informações e pensamentos que podem ser compreendidos de diversas formas de análises textuais. Dessa forma, o esquema metodológico adotado seguirá uma tendência plural para entender a história do pensamento geográfico e a evolução dos estudos sobre a relação campo-cidade, partindo da explicação do pluralismo metodológico e 
da escolha dos métodos, em seguida, abordar-se-á a questão paradigmática na ciência, pois quem estuda a história do pensamento geográfico tende a realizar divisão ou classificações por escolas, correntes ou linhas de pensamento. Essas divisões devem ser balizadas por um paradigma / filosofia dominante que dita à escolha das teorias e métodos daquele grupo de cientistas.

Neste caso, Kuhn (1975) explica essa mudança de paradigmas na ciência servindo de referência aos estudos de história do pensamento geográfico e através de suas idéias, fez-se a subdivisão teórico-metodológica e os estudos da relação campo-cidade, ou seja, como as pesquisas dos espaços rurais e urbanos acompanharam a evolução da ciência geográfica.

Foram selecionados dez periódicos brasileiros em geografia, com no mínimo dez anos de circulação: A Revista Brasileira de Geografia (RBG) que circulou entre 1939 a 2005, totalizando 219 edições publicadas; Boletim Geográfico (BG) que circulou entre 1943 a 1978, totalizando 258 edições; Boletim Paulista de Geografia (BPG) que iniciou as atividades em 1949 e circula até hoje, totalizando 88 edições; Boletim de Geografia Teorética (BGT) que circulou entre 1971 a 1995, totalizando 50 edições publicadas; Geografia (Rio Claro) que iniciou as atividades em 1976 e circula até hoje, totalizando 80 edições; Boletim Goiano de Geografia (BGG) que iniciou as atividades em 1982 e circula até hoje, totalizando 37 edições; Terra Livre que iniciou as atividades em $1986 \mathrm{e}$ circula até hoje, totalizando 33 edições; Geosul que iniciou as atividades em 1986 e circula até hoje, totalizando 48 edições; Sociedade \& Natureza que iniciou as atividades em 1989 e circula até hoje, totalizando 42 edições; Geousp que iniciou as atividades em 1997 e circula até hoje, totalizando 26 edições. No montante dos periódicos consultados, chegou-se a 881 revistas com 691 artigos de geografia agrária (Figura 1).

Figura 1 -Esquema metodológico da investigação.

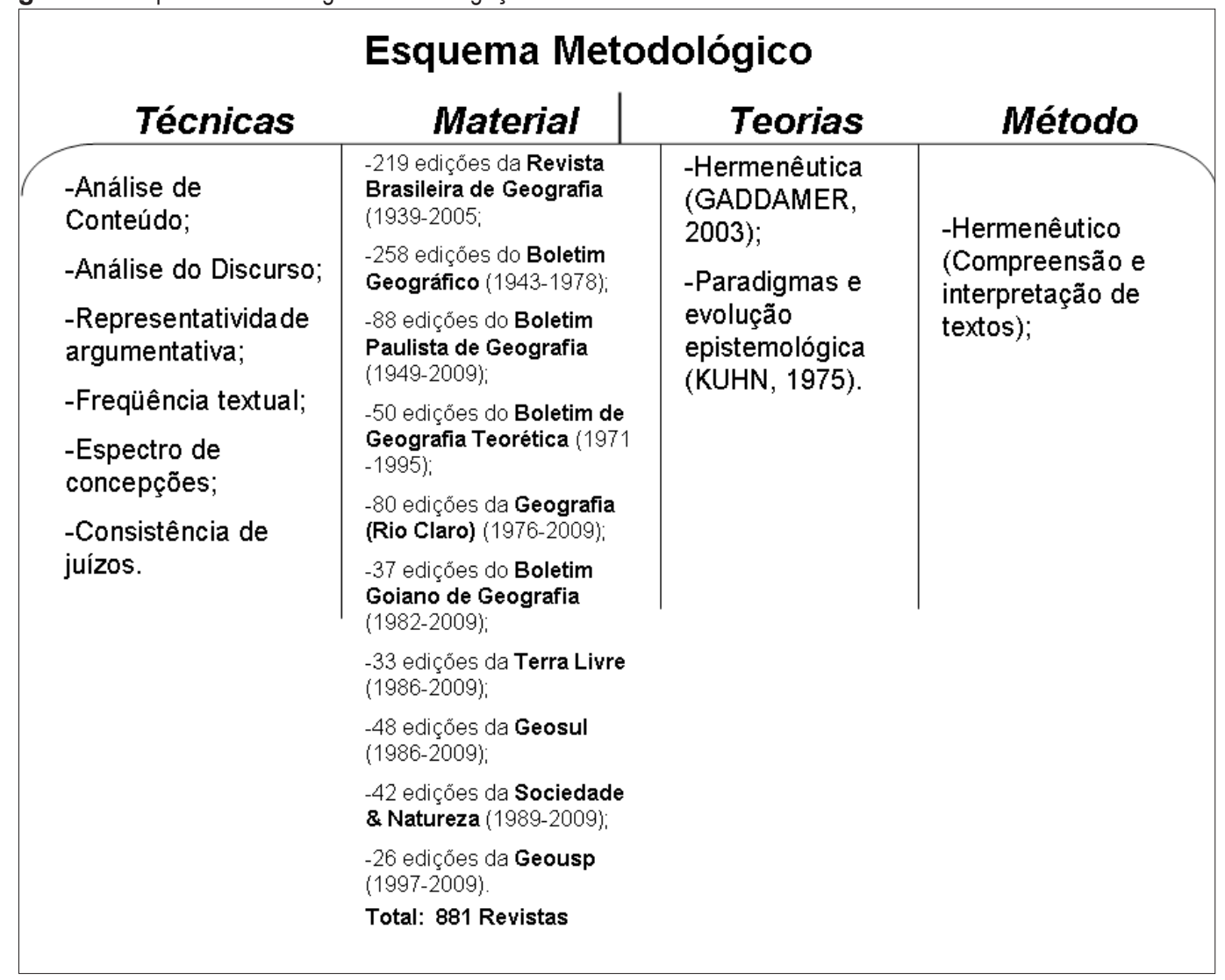

Fonte: Alves (2010, p.35).

Nos estudos lingüísticos, o método hermenêutico baseado em Gaddamer (2003) satisfez as necessidades propostas de compreensão dos textos escritos, analisando o contexto históricotextual e as concepções do autor, precisamente aquilo que Reis Júnior (2008) chama de "espectro de concepções no tempo" e "consistência de juízos". As informações quantificáveis e discursivas no texto

Geografia Ensino \& Pesquisa, v. 16, n.3 p. 7- 18, set./dez. 2012

Alves, F. D

ISSN 2236-4994 
2 Destacam-se Pierre Monbeig, Pierre Deffontaines, Albert Demangeon, Jean Brunhes, Francis Ruellan entre outros que passaram pelo Brasil. foram entendidas pelas técnicas de análise de conteúdo e discurso, formando a "representatividade argumentativa" e "frequência textual" exemplificada por Reis Júnior (2008). Uma das técnicas utilizadas foi à seleção e grupamento das palavras-chave nos resumos dos artigos que continham esses elementos, que serviu para a caracterização e classificação das abordagens dos artigos analisados e a tendência paradigmática dos trabalhos.

Além das referências técnicas e metodológicas de Reis Júnior (2008), o processo investigativo na história do pensamento geográfico, principalmente as questões teórico-metodológicas, já foram estudadas em Alves e Ferreira (2007, 2008a, 2008b, 2009, 2011), Galvão (1991), Neves (2010) e Alves e Maia (2009).

Enquanto Alves e Ferreira detalharam a evolução da geografia agrária nas questões teóricas e metodológicas, Galvão (1991) também destacou esse tema, mas enfatizou a tendência dos estudos sobre a relação campo-cidade no início da década de 1990, em especial, sob o prisma da fenomenologia e da percepção das populações desses espaços, ou seja, o geógrafo não deve pesquisar a relação campo-cidade somente pelo viés mercadológico, produtivista e economicista destes espaços, mas sim ressaltar a pluralidade de concepções e áreas que integram esses espaços.

No trabalho de Neves (2010) a autora faz um levantamento dos estudos sobre a questão campo-cidade nos anais dos Encontros Nacionais de Geografia Agrária relacionando com as quatro categorias do espaço geográfico proposta por Milton Santos: Estrutura, Processo, Forma e Função, ou seja, como os estudos da relação campo-cidade balizaram essas quatro categorias e sua aproximação com a história da geografia.

Alves e Maia (2009) fizeram uma análise comparativa de quatro autores acerca da relação campo-cidade, destacaram o estudo de Leo Waibel enfocando as paisagens rurais e a pouca ligação com a cidade, Von Thünen e a espacialidade das atividades agropecuárias entorno da cidade, Christaller e a rede urbana e por fim, Lefebvre e a constituição do espaço urbano.

Todo material utilizado nesse artigo foi consultado na Biblioteca da Universidade Estadual Paulista, Campus Rio Claro e através de consultas no sítio da Biblioteca Digital do IBGE, a qual disponibiliza todas as edições da Revista Brasileira de Geografia e boa parte dos exemplares do Boletim Geográfico, além da consulta nos periódicos via internet e dos trabalhos realizados no Núcleo de Estudos Agrários (NEA) na UNESP Rio Claro.

A análise dos artigos publicados nos periódicos em geografia foi realizada em uma seqüência temporal por correntes do pensamento geográfico e como os estudos da relação campo-cidade foram explorados gerando nos resultados um quadro sintético das características gerais dessa temática na ciência geográfica.

\section{A relação campo-cidade na perspectiva clássica da ciência geográfica}

Entendendo a geografia clássica como o princípio da cientificidade desta ciência carregada de descrições, induções e comparações, as pesquisas realizadas nesse período (1930 a 1970 aproximadamente) têm uma forte influência da geografia francesa, sobretudo de Paul Vidal de La Blache e seus discípulos ${ }^{2}$. Deste modo, os estudos sobre o campo e cidade focalizam as análises em questões de gêneros de vidas (urbanos e rurais), o habitat, os sistemas agrícolas, a economia urbana e as infra-estruturas / construções das cidades. Destaca-se a pouca integração desses espaços, os processos são gerados e desenvolvidos em espaços distintos.

Um dos primeiros artigos nessa perspectiva é de Deffontaines (1944), onde verifica a organização da rede de cidades no Brasil, através do surgimento e criação das aglomerações urbanas. $\mathrm{O}$ autor destaca que no Brasil, durante três séculos, o povoamento sempre se deu nos espaços rurais, em especial, nas fazendas e lavouras e que nunca se constitui vilas urbanas, independentes dos espaços rurais, ou seja, o campo determinava a dinâmica espacial urbana:
A relação campo-cidade apontamentos teóricos a partir de periódicos científicos 
O país, entretanto não parecia orientar-se para formas de povoamento aglomerado. Tivemos ocasião de estudar a semeadura da população rural que é essencialmente constituída por formas dispersas. Em nenhuma parte do Brasil a vila é a unidade de povoamento, esta é a grande propriedade, a fazenda, com sua colônia de empregados rurais, ora grupada em pequenas cidades operárias ora dispersa através do domínio em retiros ou currais. (DEFFONTAINES, 1944, p.141).

Outro ponto que é destacado é o surgimento de cidades ao longo das ferrovias no interior do Estado de São Paulo, Deffontaines (1944) e Monbeig $(1944,1949)$ analisam a formação de núcleos urbanos originários pela expansão da rede ferroviária que serviu para escoamento da produção de café no interior paulista, ou seja, novamente o campo dita o ritmo do crescimento urbano e das estruturas para a população da cidade.

Monbeig (1944) destaca a importância da cafeicultura, principalmente para a população e organização rural no estado de São Paulo, vai sendo aos poucos transformada com a chegada dos imigrantes italianos, alemães e japoneses e a ferrovia, que fez crescer as vilas e cidades ao longo dessa rede de transportes:

Mas a introdução de uma cultura fixa como a do café iria modificar toda a vida rural, transformar radicalmente a civilização e sua paisagem nos planaltos paulista [...] Esta paisagem rural não está ainda inteiramente abolida, mas ela só subsiste como testemunha de um passado que se esvai rapidamente. (MONBEIG, 1944, p.429).

Outro tema explorado na corrente clássica é a questão do abastecimento desenvolvido por Bertha Becker (1966), La Corte (1976) e Manuel Seabra (1969), ou seja, a dependência da cidade frente a produção agrícola é destacada como uma das relações existentes entre campo-cidade.

Assim, a questão entre campo-cidade é muito ínfima nos estudos da geografia clássica, pouca integração há nesse período (Figura 2).

Figura 2 - Relação campo-cidade nos estudos clássicos da geografia - 1930 a 1960.

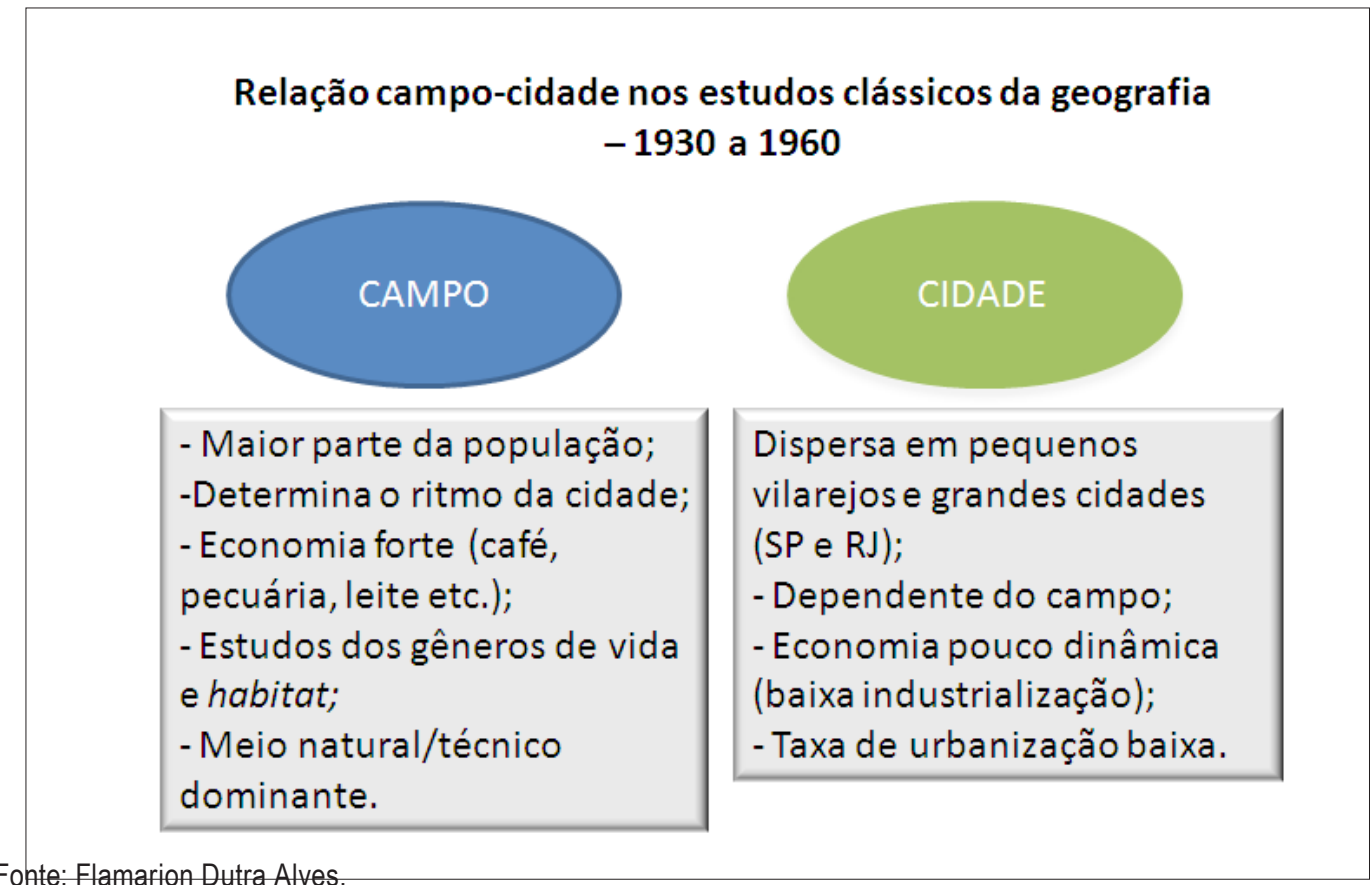

Geografia Ensino \& Pesquisa, v. 16, n.3 p. 7- 18, set./dez. 2012 
Dessa forma, a dinâmica espacial do campo e cidade é tratada de forma separada ou pouco integrada, sendo abordado como causa e conseqüência de um espaço para outro ou o reflexo da atividade rural na cidade.

\section{Os estudos teoréticos na questão campo-cidade}

Os elementos teorético-quantitativos deram novas características a ciência geográfica, a "necessária" aplicabilidade e cientificidade da geografia frente às outras ciências humanas - sociais. O uso contundente de técnicas estatísticas, modelos matemáticos e, essencialmente, uma filosofia neopositivista (lógico formal) que deu suporte para suas teorias e métodos foram marcantes entre o final da década de 1960 até meados da década de 1980 no Brasil.

Mesquita (1978) desenvolveu o trabalho a respeito do uso do modelo de Von Thünen para a espacialidade das atividades agropecuárias e o comportamento do campo e cidade nesse esquema. O modelo de Von Thünen também foi utilizado por Geiger, Lima e Abib (1974) entorno de São Paulo, para identificar e tipificar as regiões agropastoris (Figura 3).

Figura 3 - Utilização do modelo de von Thünen no Brasil.

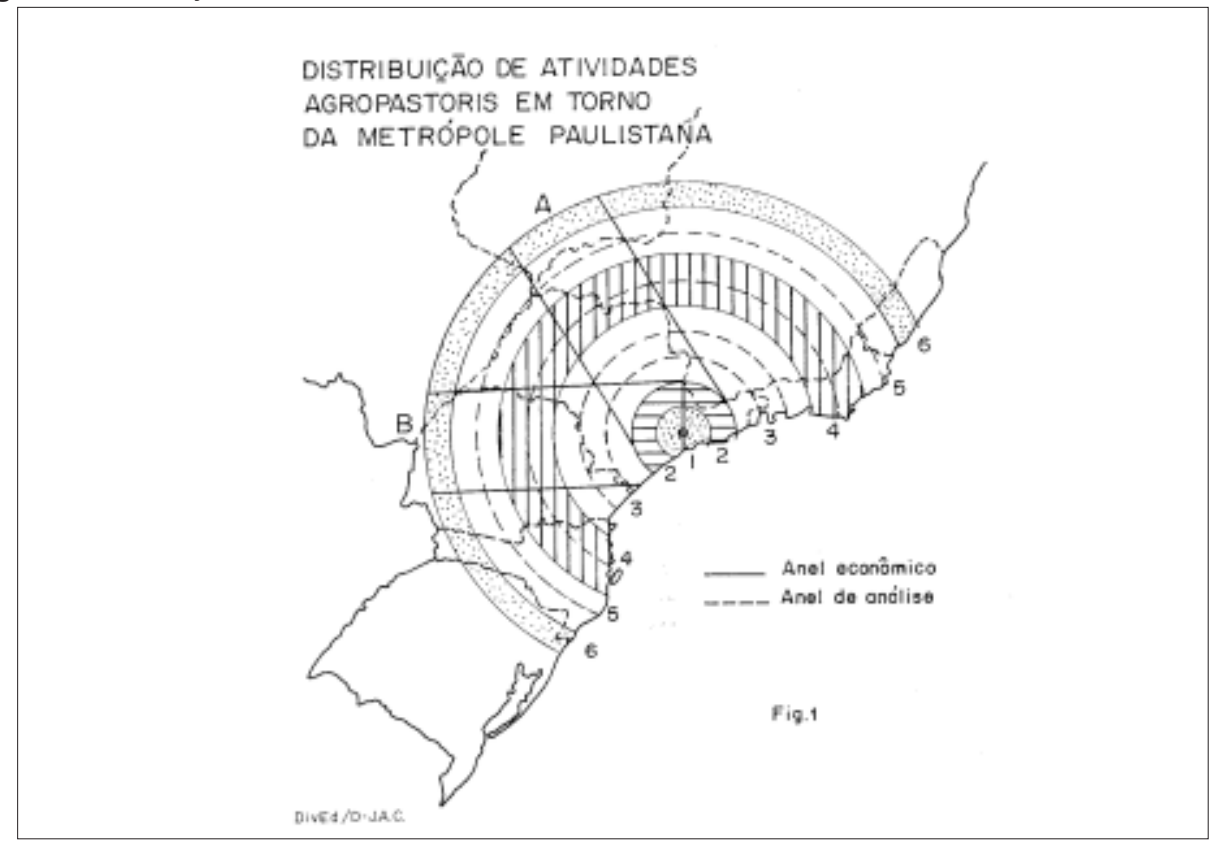

Fonte: Geiger, Lima e Abib (1974, p.7).

O modelo teórico de Von Thünen foi amplamente difundido nas investigações no espaço agrário, pois dá a noção da localização e distribuição espacial das atividades econômicas, como as formas e elementos estão organizados no espaço e como se inter-relacionam, além de interpretar a distâncias das culturas agropecuárias em relação aos centros urbanos, ou seja, a cidade torna-se o centro da relação com o campo.

La Corte (1976) ainda na questão da distância e comercialização agropecuária estudou o

Geografia Ensino \& Pesquisa, v. 16, n.3 p. 7-18, set./dez. 2012

A relação campo-cidade na Geografia brasileira: apontamentos teóricos a partir de periódicos científicos abastecimento hotifrutícola da cidade de São Paulo, mostrando de forma gráfica e cartográfica as origens das mercadorias, além das quantidades de alguns alimentos, chegando como resultado a classificação de zonas e setores hortifrutícolas no Estado de São Paulo, ou seja, um trabalho que se preocupou com a dinâmica espacial da geografia agrícola em relação à cidade.

O trabalho de Miranda (1980) entra na questão dos espaços periféricos que são ocupados pela grande urbanização na década de 1970 no município do Rio de Janeiro, a autora destaca dois conceitos importantes nessa análise integrada: franja urbano-rural, suburbana e espaços periurbanos: 
Mais recentemente, a expansão da cidade está se voltando para a sua franja urbano-rural em direção oeste, representada pela planície de Jacarepaguá, caracterizada como um enclave que, em grande parte, ficara preservado do processo de ocupação. A expansão urbana para esta área está se fazendo através de dois vetores. Um, seguindo a orla litorânea, acompanha a faixa de amenidades [...] 0 outro, partindo da borda norte da planície, atinge o seu interior e complementa a tendência da ocupação. (MIRANDA, 1980, p.276). (grifo nosso).

Na questão periurbana e suburbana a autora releva essa ligação do campo e cidade no município do Rio de Janeiro ocorre desde o final do século XIX:

No começo do século teve início à ocupação que incorporaria a planície de Jacarepaguá como franja urbano-rural da cidade [...] a ocupação, representando 0 avanço da cidade a partir de sua parte norte suburbana para a área rural, resultou em uma primeira modificação no uso do solo da área isolada [...] nesse avanço da frente de ocupação periurbana verifica-se inicialmente o parcelamento das grandes fazendas em sítios, fenômeno que vinha ocorrendo já no final do século XIX. (MIRANDA, 1980, p.278). (grifo nosso).

Assim, o campo e cidade são estudados de forma mais integrada na geografia, com a questão do abastecimento, espaços periurbanos, suburbanos e franjas urbano-rurais (Figura 4).

Figura 4 - Relação campo-cidade nos estudos teoréticos da geografia - 1960 a 1980.

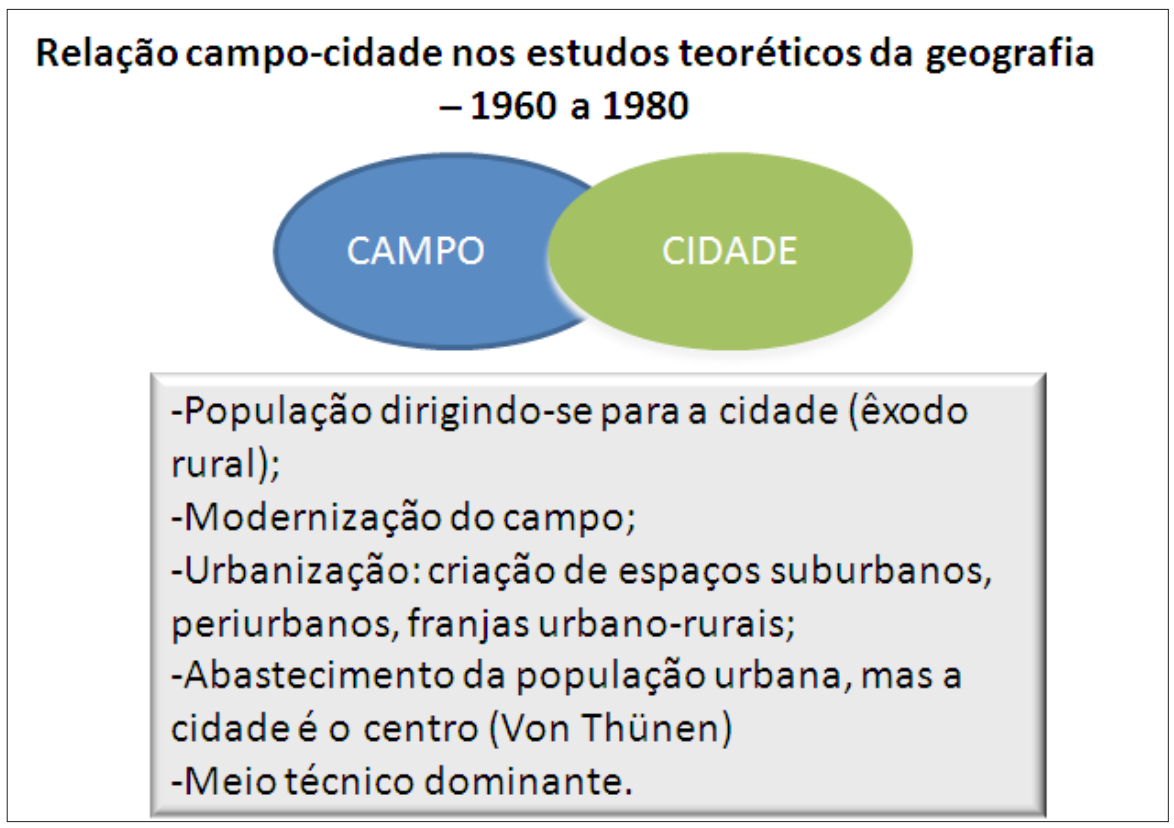

Fonte: Flamarion Dutra Alves.

Portanto, a geografia teorética através dos modelos matemáticos e espaciais deu ênfase a distribuição e organização do espaço, preocupando-se com a caracterização e função do campo e cidade. Entretanto, a visão mais funcional e cartográfica dessas pesquisas sobrepujaram a questão social e crítica da população, o caráter político e desigualdade socioespacial (assim, como os estudos da geografia clássica).

Geografia Ensino \& Pesquisa, v. 16, n.3 p. 7- 18, set./dez. 2012 


\section{A Geografia Crítica e as dinâmicas entre campo-cidade - a tendência pós 1990 na Geografia}

A Geografia Nova, Crítica ou Social, surge no fim da década de 1970 no Brasil, com o intuito de aproximar às ciências sociais no arcabouço teórico-metodológico, prestando serviço à sociedade, denunciando e expondo os problemas gerados pelo processo histórico de formação do território brasileiro. O pensamento social e econômico na geografia agrária foi fortemente influenciado pela aproximação com as bases marxistas, a partir da década de 1980. Até então, faziam-se poucas críticas sobre as relações de trabalho, concentração de terras e o desenvolvimento desigual no campo, e quando aconteciam às críticas, essas não eram baseadas num referencial históricodialético, ou seja, a grande mudança na crítica sobre as desigualdades agrárias foi na inserção do método.

A modernização na agricultura da década de 1970 transformou as relações produtivas, integrando o campo com a cidade, agricultura e indústria. Sobre a modernização e a geografia agrária Ferreira (2002, p.288) afirma:

Considerando que o sentido das mudanças foi dado em direção à consolidação das relações campo-cidade, evidenciadas pelos papéis que passaram a exercer a agricultura e a indústria na economia nacional, os estudos de Geografia Agrária deixaram de ser tipicamente agrícolas e incorporaram de forma definitiva a vertente social como definidora da postura geográfica sobre 0 assunto.

Após a década de 1990, muitos estudos na geografia agrária e urbana partiram para as interpretações das inter-relações dos espaços contínuos, conforme lembra Alves e Ferreira (2011 p.11):

O espaço rural foi altamente alterado com esse incremento de tecnologias e a aproximação das relações industriais em boa parte do campo brasileiro, mas esta mudança vem sendo realizada paulatinamente desde a década de 1960, sendo acelerada pós 1990. Nesse sentido, as temáticas sobre a relação campo e cidade ou urbanização do campo vem ganhando força no discurso geográfico brasileiro.

3 Convém lembrar os estudos de Alexander Chayanov sobre a reprodução do campesinato, e uma das estratégias era a produção não-agrícola.

Geografia Ensino \& Pesquisa, v. 16, n.3 p. 7-18, set./dez. 2012

A relação campo-cidade na Geografia brasileira: apontamentos teóricos a partir de periódicos científicos

14

ISSN 2236-4994
É importante frisar que a reestruturação da agropecuária não homogeneizou a produção ou os espaços agrícolas, nem tão pouco os espaços urbanos que crescem com este processo. 0 que ocorre em contraposição ao processo de globalização da produção e do consumo agropecuário é um intenso processo de fragmentação da produção e do espaço agrícola. Assim sendo, como recurso de método para compreensão da urbanização brasileira, do espaço agrário e das 
cidades do agronegócio, temos que considerar esta fragmentação, que torna cada vez mais diferenciados os espaços agrícolas e as cidades do agronegócio. (ELIAS \& PEQUENO, 2005, p.30).

Outro ponto que os autores destacam é a formação de cidade do campo, com base nos aportes teóricos de Milton Santos:

\begin{abstract}
Uma das conseqüências da reestruturação produtiva da agropecuária no Brasil é o processo de urbanização e crescimento urbano, promovidos, entre outros, pelas novas relações campo-cidade, desencadeadas pelas necessidades do consumo produtivo agrícola, que cresce mais rapidamente do que o consumo consumptivo. Segundo Santos, na medida em que é a cidade que passa a fornecer a grande maioria dos produtos, serviços e mão-de-obra necessários à produção agropecuária e agroindustrial modernas, algumas cidades locais e mesmo intermediárias deixam de ser a cidade no campo e se transformam na cidade do campo. (ELIAS \& PEQUENO, 2005, p.20).
\end{abstract}

Assim, a relação campo-cidade no final do século XX e neste início de século mostra uma multiplicidade de estudos e temáticas na geografia contemporânea (Figura 5).

Figura 5 - Relação campo-cidade nos estudos contemporâneos da geografia - 1990 a 2009.

\title{
Relação campo-cidade nos estudos críticos / contemporâneos da geografia - 1980 a 2009
}
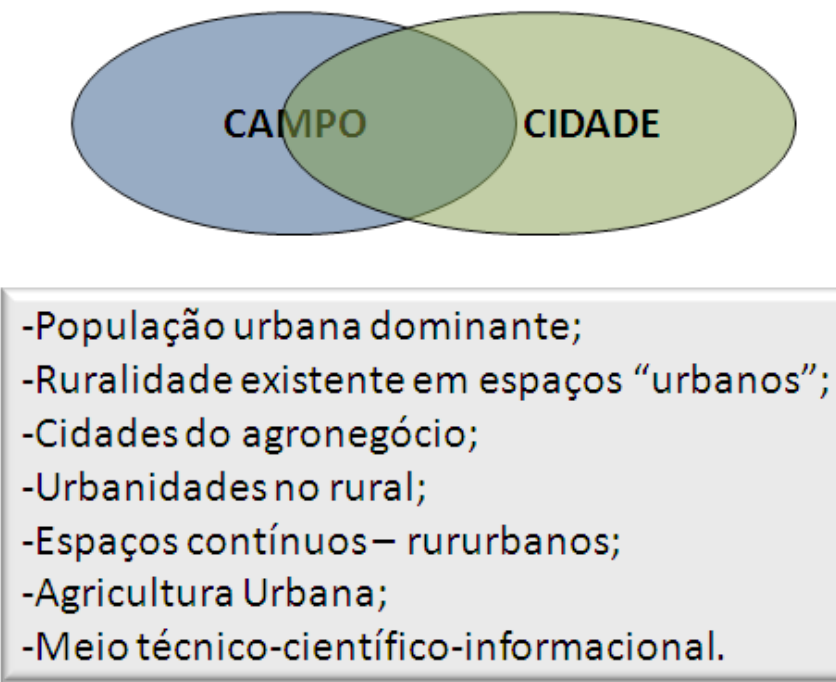

Fonte: Flamarion Dutra Alves.

\section{Considerações finais}

A realidade espacial se torna cada vez mais dinâmica e complexa, com a modernização do campo, tecnologias, cientificidade e urbanização, conforme apontam Alves e Ferreira (2011, p.14) 
relação campo-cidade, questões ambientais, sustentabilidade entre outros temas que emergem da necessidade de explicação das realidades cada vez mais dinâmicas.

Dessa forma, a geografia agrária e geografia urbana devem caminhar juntas nas questões teórico-metodológicas ao tratarem do espaço, pois existem relações econômicas, socioespaciais, populacionais, culturais e ambientais que estão em constante interdependência. E esta pesquisa evidenciou a relação presente ao longo da história da geografia (Quadro 1).

Quadro 1 - Sistematização das características dos estudos da relação campo-cidade nas escolas geográficas.

\begin{tabular}{|c|c|c|c|}
\hline $\begin{array}{c}\text { Características I } \\
\text { Escolas }\end{array}$ & Geografia Clássica & Geografia Teorética & Geografia Crítica \\
\hline Forma e Função & $\begin{array}{c}\text { Campo: Produção de } \\
\text { alimentos. }\end{array}$ & $\begin{array}{c}\text { Campo: Produção de } \\
\text { alimentos. }\end{array}$ & $\begin{array}{c}\text { Espaços com atividades } \\
\text { Compostas/mistas - } \\
\text { multifuncionalidade }\end{array}$ \\
\hline Estrutura e Processo & $\begin{array}{c}\text { Cidade: Fixação dos serviços } \\
\text { e indústria. }\end{array}$ & $\begin{array}{c}\text { Cidade: Fixação dos } \\
\text { serviços e indústria. }\end{array}$ & Espaços contínuos \\
\hline Conceitos & $\begin{array}{c}\text { Campo determina o ritmo das } \\
\text { cidades. }\end{array}$ & $\begin{array}{c}\text { Franja urbano-rural - } \\
\text { periferias da cidade. }\end{array}$ & $\begin{array}{c}\text { Rururbano; Novo Rural; } \\
\text { Urbanidade; Ruralidades. }\end{array}$ \\
\hline Temáticas & $\begin{array}{c}\text { Gêneros de vida; Habitat; } \\
\text { Região; Paisagem. }\end{array}$ & $\begin{array}{c}\text { Redes urbanas; } \\
\text { Regionalização; Espaços } \\
\text { periurbanos. }\end{array}$ & $\begin{array}{c}\text { Agronegócio; Pluriatividade; } \\
\text { Multifuncionalidade; } \\
\text { Agricultura urbana. }\end{array}$ \\
\hline Conceitos & $\begin{array}{c}\text { Imigração; Colonização; } \\
\text { Ferrovias; Abastecimento. }\end{array}$ & $\begin{array}{c}\text { Modernização do campo; } \\
\text { urbanização. }\end{array}$ & $\begin{array}{c}\text { Rururbano; Novo Rural; } \\
\text { Urbanidade; Ruralidades. }\end{array}$ \\
\hline Temáticas & $\begin{array}{c}\text { Imigração; Colonização; } \\
\text { Ferrovias; Abastecimento. }\end{array}$ & $\begin{array}{c}\text { Modernização do campo; } \\
\text { urbanização. }\end{array}$ & $\begin{array}{c}\text { Agronegócio; Pluriatividade; } \\
\text { Multifuncionalidade; } \\
\text { Agricultura urbana. }\end{array}$ \\
\hline
\end{tabular}

Organização: Flamarion Dutra Alves.

Assim, pode-se fazer uma perspectiva para este início de século XXI quanto à categoria de análise geográfica, que ainda é o espaço, mas abordado de uma forma multidimensional e complexo entendo suas diversas relações espaciais, como a questão campo-cidade, multifuncionalidade do espaço rural entre outros.

A noção de ruralidade e urbanidade ganha destaque nas pesquisas em geografia, pois não trata somente da questão espacial (do espaço absoluto), mas o espaço vivido e imaterial, considerando os valores e o modo de vida que constituem o lugar. A ideia de estudar o espaço apenas pelos fixos, funções e formas, não responde a totalidade da relação campo-cidade, deve-se atentar aos processos da sociedade.

\section{Referências}

Geografia Ensino \& Pesquisa, v. 16, n. 3 p. 7-18, set./dez. 2012

A relação campo-cidade na Geografia brasileira: apontamentos teóricos a partir de periódicos científicos
ALENTEJANO, Paulo R. O que há de novo no rural brasileiro? p.87-112. Terra Livre. n.15, 2000. As relações campo-cidade no Brasil do século XXI. p.25-39. Terra Livre. n.21, $2^{\circ}$ sem. 2003.

ALVES, Flamarion Dutra. Trajetória teórico-metodológica da geografia agrária brasileira: A produção em periódicos científicos de 1939 - 2009. Tese de Doutorado (Geografia Organização do Espaço). Rio Claro: Universidade Estadual Paulista, 2010. 350p. 
ALVES, Flamarion Dutra. \& FERREIRA, Enéas Rente. Evolução e perspectivas da metodologia em Geografia Agrária. p.725-735. Seminário de pós-graduação em geografia da UNESP- Campus Rio Claro, v.7. Anais... Rio Claro: AGETEO, 2007.

Pressupostos teórico-metodológicos da geografia rural brasileira: evolução e tendências. p.1-14. Colóquio Brasileiro de História do Pensamento Geográfico, v.1. Anais... Uberlândia: UFU, 2008a.

Elementos metodológicos da geografia agrária clássica: a produção em periódicos brasileiros. p.43-61. Geo UERJ. v.2, n.18. Rio de Janeiro, 2008b.

Estudos rurais e o pensamento geográfico brasileiro: do positivismo clássico ao neopositivismo. Encontro de Grupos de Pesquisa: agricultura, desenvolvimento regional e transformações socioespaciais, v. 5. Anais... Santa Maria: UFSM, 2009.

Trajetória da geografia agrária brasileira: setenta anos de mudanças, afirmações e perspectivas. Encontro de Grupos de Pesquisa: agricultura, desenvolvimento regional e transformações socioespaciais, v. 6. Anais... Presidente Prudente, 2011.

ALVES, Flamarion D. \& MAIA, Adriano C. Teorias sobre o espaço e a questão rural-urbano. In: FERREIRA, D.A.O. \& FERREIRA, E.R. (Org) Estudos agrários: conceitos e práticas. Rio Claro: IGCE/UNESP - Pós-Graduação em Geografia, 2009. p.47-64.

BECKER, Bertha K. O mercado carioca e seu sistema de abastecimento. p.129-156. Revista Brasileira de Geografia. v.28, n.2, 1966.

DEFFONTAINES, Pierre. Como se constituiu no Brasil a rede de cidades. p.141-148. Boletim Geográfico. v.2, n.14, 1944.

DUARTE, Aluizio C. Hierarquia de localidades centrais em áreas subpovoadas: o caso de Rondônia. p.66-78. In: Encontro Nacional de Geógrafos, v.2. Anais...Belo Horizonte: AGB, 1976.

ELIAS, Denise \& PEQUENO, Renato. Espaço urbano no Brasil agrícola moderno e desigualdades socioespaciais. p.13-33. Terra Livre. n.25, 2005.

FERREIRA, Darlene Ap. O. Mundo rural e geografia - geografia agrária no Brasil: 19301990. São Paulo: Editora UNESP, 2002.

GADAMER, Hans-Georg. Verdade e método. 5.ed. Tradução Flávio Paulo Maurer. Petrópolis: Vozes, 2003.

GALVÃO, Maria do Carmo C. Contribuição ao debate metodológico da geografia agrária. p.45-52. Anuário do Instituto de Geociências. v.14, 1991.

GEIGER, Pedro Pinchas; LIMA, Maria Salette Ney da Motta; ABIB, Myriam Emile Abi. Distribuição de atividades agropastoris em torno da metrópole de São Paulo. p.3-36. Revista Brasileira de Geografia. v.36, n.4, 1974.

HESPANHOL, Antonio Nivaldo \& HESPANHOL, Rosângela Aparecida de Medeiros. Dinâmica do espaço rural e novas perspectivas de análise das relações campo-cidade no Brasil. p.133-148. Terra Livre. v.2, n.27, 2006.

KUHN, Tomas S. A estrutura das revoluções científicas. São Paulo: Perspectiva, 1975.

Geografia Ensino \& Pesquisa, v. 16, n.3 p. 7- 18, set./dez. 2012

Alves, F. D 
LACORTE, Judith de. Abastecimento da cidade de São Paulo em produtos hortifrutícolas: problemas e métodos de estudo. p.29-54. Boletim Paulista de Geografia. v.52, out. 1976.

MESQUITA, Olindina Vianna. O modelo de von Thünen: uma discussão. p.60-130. Revista Brasileira de Geografia. v.40, n.2, 1978.

MIRANDA, Maria H.P. Crescimento periférico da cidade do Rio de Janeiro: padrões espaciais da ocupação residencial. p.265-309. Revista Brasileira de Geografia. v.42, n.2, 1980.

MONBEIG, Pierre. Notas relativas à evolução das paisagens rurais no Estado de São Paulo. p.428430. Boletim Geográfico. v.2, n.16, 1944.

Evolução de gêneros de vida rurais tradicionais no sudeste do Brasil. p.980-987. Boletim Geográfico. v.7, n.81, 1949.

NEVES, Karina F. T. V. Relação cidade-campo, geografia agrária brasileira e as transformações na organização do espaço geográfico: síntese dos fenômenos envolvidos. p.2809-2829. I Congresso Brasileiro de Organização do Espaço e X Seminário de Pós-Graduação em Geografia da UNESPRio Claro. Anais... Rio Claro: AGETEO, 2010.

REIS JÚNIOR, Dante Flávio da Costa. História do Pensamento Geográfico: como lê-lo para interpretá-la? (as rotinas técnicas). p.596-605. Simpósio de Pós-Graduação em Geografia do Estado de São Paulo - $1^{\circ}$ SIMPGEO. Anais...Rio Claro: AGETEO, 2008.

RUA, João. A resignificação do rural e as relações cidade-campo: uma contribuição geográfica. p.45-66. Revista da ANPEGE. v.2 , 2005.

SEABRA, Manuel. Plano da coleta para a pesquisa sobre o "Abastecimento da cidade de São Paulo em gêneros alimentícios”. p.65-78. Boletim Geográfico. v.28, n.209, 1969.

\section{Correspondência:}

Flamarion Dutra Alves - Rua Francisco Mariano, 384. ap. 1101. Centro. Alfenas - MG. CEP: 37130-000.

E-mail: dutrasm@yahoo.com.br

Recebido em 19 de fevereiro de 2012.

Revisado pelo autor em 27 de março de 2012.

Aceito para publicação em 10 de abril de 2012. 